\title{
Co-seismic energy release and relevant region of Tohoku $M 9.0$ earthquake
}

\author{
LU MingFu ${ }^{1,2}$, LI Li $^{3 *}$, XIA MengFen ${ }^{4}$, WANG HaiYing ${ }^{1} \&$ BAI YiLong ${ }^{1}$ \\ ${ }^{1}$ State Key Laboratory of Nonlinear Mechanics (LNM), Institute of Mechanics, Chinese Academy of Sciences, Beijing 100190, China; \\ ${ }^{2}$ Graduate University of Chinese Academy of Sciences, Beijing 100049, China; \\ ${ }^{3}$ National Earthquake Infrastructure Service, China Earthquake Administration, Beijing 100036, China; \\ ${ }^{4}$ Department of Physics, Peking University, Beijing 100871, China
}

Received April 12, 2011; accepted April 28, 2011; published online May 20, 2011

Citation: $\quad$ Lu M F, Li L, Xia M F, et al. Co-seismic energy release and relevant region of Tohoku M9.0 earthquake. Sci China Earth Sci, 2011, 54: 947-950, doi: 10.1007/s11430-011-4229-7

"Off the Pacific coast of Tohoku Earthquake" (M9.0, on March 11th, 2011) is the greatest one in Japanese seismic record. The hypocenter is located $130 \mathrm{~km}$ ESE off the Pacific coast of Tohoku with the focal depth of $24 \mathrm{~km}$. The quake-triggered tsunami afterward seriously damaged the nuclear reactors and caused severe consequences to the society [1].

The main shock of the Tohoku Earthquake lasted for about $140 \mathrm{~s}$ [2] and hundreds of aftershocks occurred during the next couple of days [1]. On March 25th, 2011, Okada, the president of NESC, gave a preliminary report on the earthquake as follows [1]. This earthquake is of thrust type, caused by the rebound of a continental plate (North American) against a subducting oceanic plate (Pacific) at the Japan Trench. The rupture (offset of rock) is initiated from a hypocenter and spreads to make a planar cut surface. But, the gigantic energy of $M 9.0$ earthquake was never radiated only from the hypocenter and the amount of offset determines the magnitude of the earthquake [1]. If so, what specific amount of rock offset the gigantic energy comes from and how large the relevant region is become the two key issues in understanding the earthquake.

According to our experimental and theoretical study of catastrophic rupture in heterogeneous media, such as rocks, catastrophic rupture should be a self-sustainable process. That is to say, during a catastrophic rupture, the elastic energy released from the unloading zone should afford all dissipations in the rupture, including the dissipation in rupture zone, radiating stress waves, etc. [3-5]. In this paper, based on the GPS observations available now, the distribution of co-seismic incremental strains are reconstructed first, and then the elastic energy released from an unloading region is calculated and compared to the energy involved in seismic waves. The comparison of the two energies is in reasonable agreement and the reconstructed incremental strain field clearly highlights the region, which makes the major contribution to the earthquake.

\section{Method and results}

The main shock and the aftershocks of Tohoku Earthquake

Table 1 The two faults of rupture zone in Tohoku Earthquake [6]

\begin{tabular}{cccccccc}
\hline & Latitude $(\mathrm{N})$ & Longitude $(\mathrm{E})$ & Length $(\mathrm{km})$ & Width $(\mathrm{km})$ & Strike $\left(^{\circ}\right)$ & Dip $\left(^{\circ}\right)$ & Rake $\left({ }^{\circ}\right)$ \\
\hline Fault 1 & $39.00^{\circ}$ & $143.49^{\circ}$ & 199 & 85 & 202 & 18 & 97 \\
Fault 2 & $37.21^{\circ}$ & $142.52^{\circ}$ & 176 & 82 & 201 & 15 & 81.7 \\
\hline
\end{tabular}

*Corresponding author (email: lilygrace@neis.gov.cn) 
were concentrated on two faults, see Figure 1 and Table 1 [6]. To facilitate the following analysis of the deformation field of Tohoku Earthquake, a local coordinate system XOY is set, where $X$-axis and $Y$-axis are parallel and perpendicular to the faults' strike respectively (see Figure 1). The origin of the coordinates is set at the location of Tohoku Earthquake.

We adopt Bi-Harmonic Interpolation Spline method [7, 8] to fit the co-seismic displacements based on GPS observation data [6] and to reconstruct the incremental displacements and strains in a half space limited by the faults, namely $Y>0$. Since there are no GPS observations available in the sea, we assumed that a cubic polynomial fitting (consistent with the adopted Bi-Harmonic Interpolation Spline method) of the GPS observations in inland could represent the variations in the region between the coast and the fault, see Figure 2. Actually, as shown in Figure 2, this cubic polynomial fitting leads to a co-seismic $Y$-displacement near hypocenter over 10 meters. Noticeably, on April 6th, 2011, the Japan Coast Guard announced that according to their observations, the sea bed near the hypocenter moved about $24 \mathrm{~m}$ southeastward [9]. So, the extrapolation into the sea seems to be fairly reasonable.

Thus, the $X$ - and $Y$-components of co-seismic incremental displacements $\Delta U$ and $\Delta V$ are reconstructed with Bi-harmonic Spline Interpolation. Since the component $\Delta U$ is much less than $\Delta V$, only the $Y$-component $\Delta V$ is given in

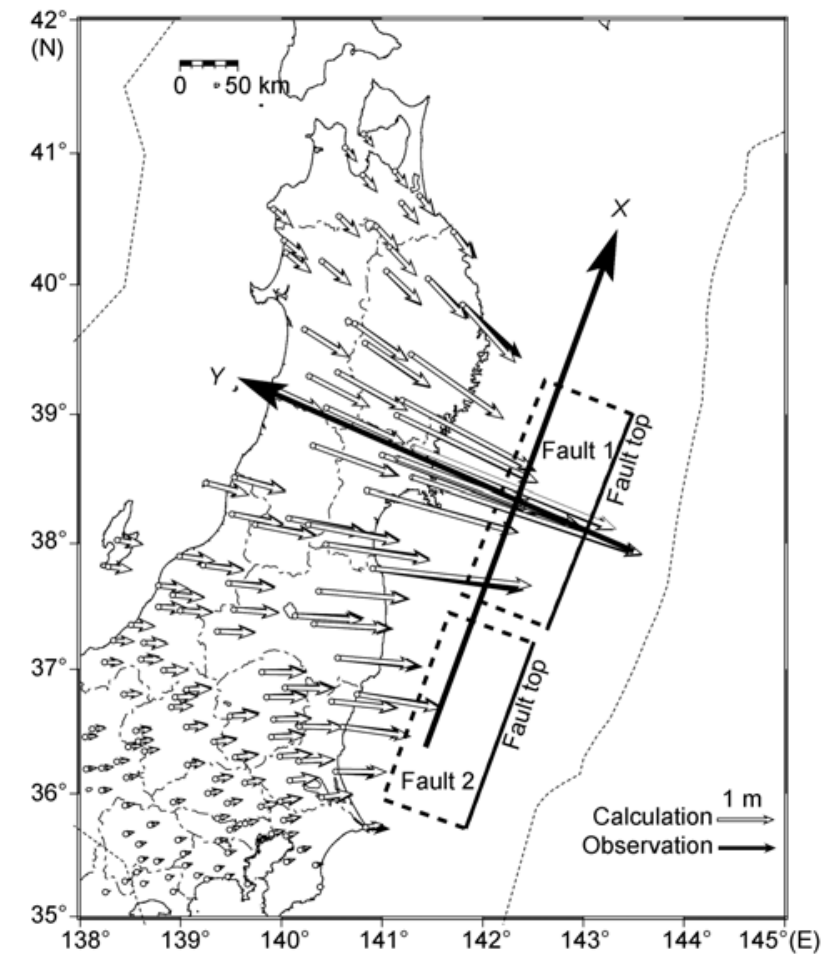

Figure 1 The co-seismic horizontal displacement and the two faults involved in Tohoku Earthquake with the local coordinate $X O Y$. The origin of the coordinate $X O Y$ is the hypocenter of the main shock in Tohoku Earthquake [6].
Figure 3. Then, the incremental strains can be obtained with difference calculation and, as above, only the incremental normal strains $\Delta \varepsilon_{Y}$ perpendicular to the faults is shown in Figure 4 , since the absolute value of the other strain increment $\Delta \varepsilon_{X}$ is also very much less than that of $\Delta \varepsilon_{Y}$. The contour plot of $\Delta \varepsilon_{Y}$ in Figure 4 shows the spatial variation of the unloading (rebounded extension) strain increments. The

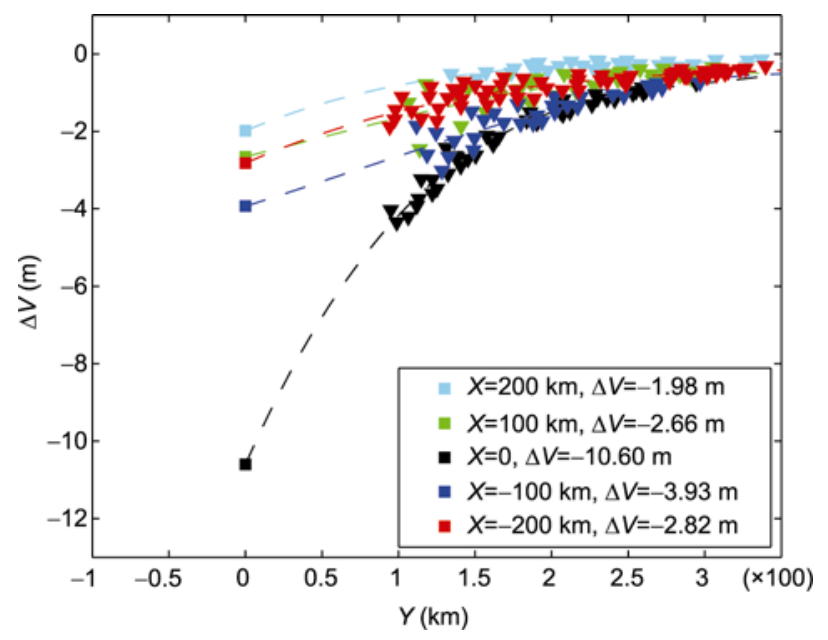

Figure 2 Five fittings at five $X$-sections on half-space $(Y>0)$ with cubic polynomial fitting based on inland GPS data. The reversed triangles denote the inland GPS data in five regions $-250 \mathrm{~km}<X<-150 \mathrm{~km},-150$ $\mathrm{km}<X<-50 \mathrm{~km},-50 \mathrm{~km}<X<50 \mathrm{~km}, 50 \mathrm{~km}<X<150 \mathrm{~km}, 150 \mathrm{~km}<X<250 \mathrm{~km}$ and the dash lines are the corresponding cubic polynomial fittings respectively. The squares denote the extrapolated values of incremental displacement $\Delta V$ at $Y=0$.

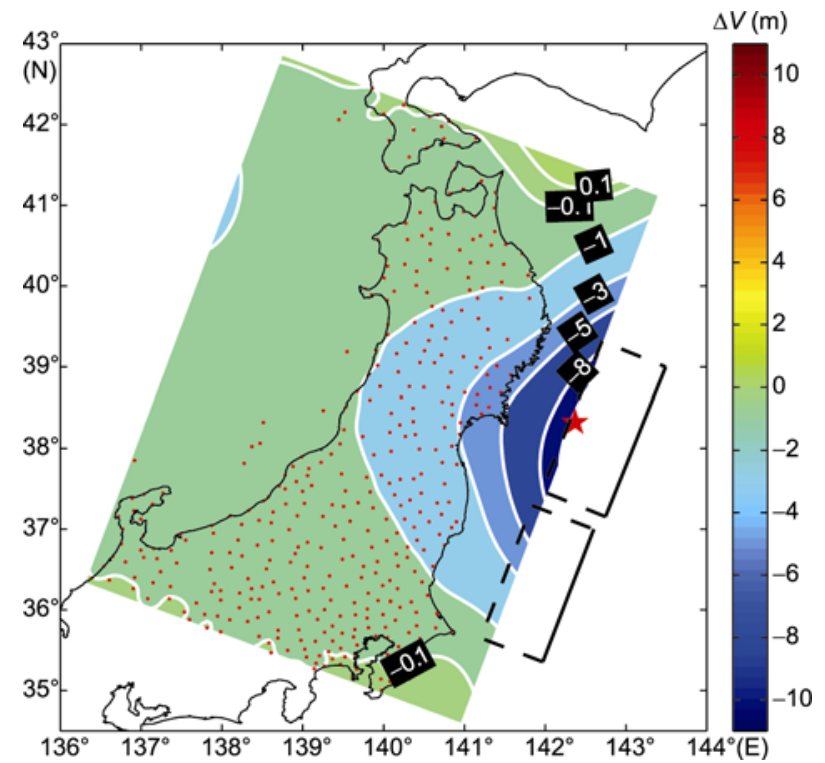

Figure 3 The distribution of the reconstructed co-seismic incremental displacement $\Delta V$. The red pentagon is the hypocenter of Tohoku Earthquake. The two rectangles are the faults of Tohoku Earthquake. The red dots stand for the locations of GPS stations. The black line is the sketch of Japan. The white lines are the iso- $\Delta V$ contours. The co-seismic incremental displacement $\Delta V$ increases sharply near the hypocenter of Tohoku Earthquake. 


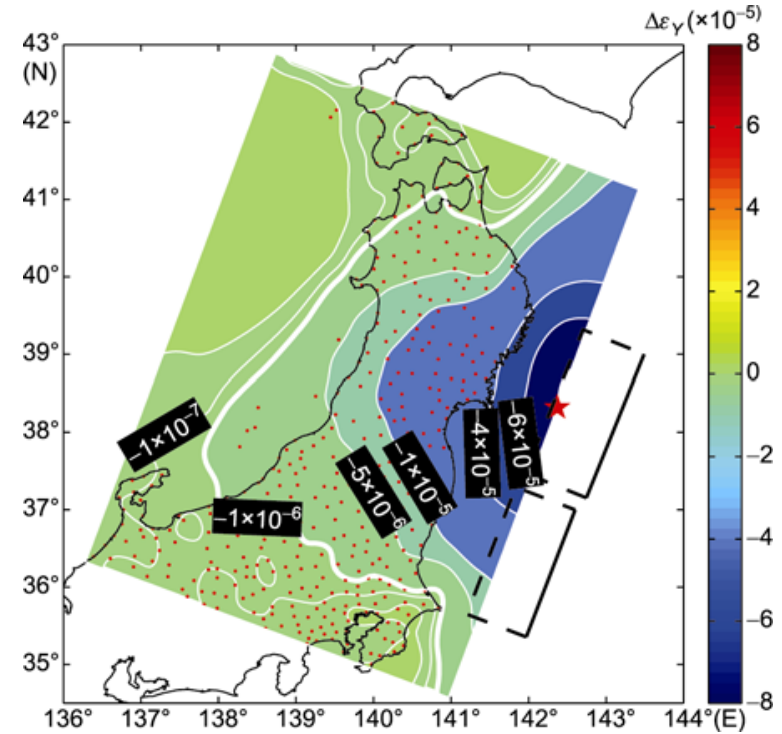

Figure 4 The distribution of reconstructed co-seismic incremental normal strain $\Delta \varepsilon_{Y}=\Delta(\Delta V) / \Delta Y$. The negative values imply rebound extension. The co-seismic incremental normal strain $\Delta \varepsilon_{Y}$ is concentrated on the region near the hypocenter of Tohoku Earthquake. And the extreme extension could attain $8 \times 10^{-5}$. The bold white contour denotes the threshold $\varepsilon_{Y, \mathrm{c}}=10^{-6}$.

distribution also indicates that the unloading normal strain increment increases as approaching the faults and the maximum of the unloading normal strain increment could reach as high as about $8 \times 10^{-5}$. And the unloading strain increments are concentrated in the region with $\left|\Delta \varepsilon_{Y}\right|>10^{-6}$, namely $0<Y<400 \mathrm{~km}$.

The unloading strain increment $\Delta \varepsilon_{Y}<0$ should be closely related to the energy release during Tohoku Earthquake owing to its elastic nature. After assuming the rupture stress $\sigma_{\mathrm{c}}$ be $\left(\sim 0.2 \times 10^{-2}\right)$ times elastic modulus $\left(\sim 5 \times 10^{10} \mathrm{~N} / \mathrm{m}^{2}\right)$, i.e., $\sigma_{\mathrm{c}} \sim 1 \times 10^{8} \mathrm{~N} / \mathrm{m}^{2}$ and the depth of crust $d \sim 24 \mathrm{~km}$, the released energy in the unloading region limited by the faults $(Y=0)$ and an outbound contour of a strain increment threshold (as $\left|\Delta \varepsilon_{Y}\right|>\varepsilon_{Y, \mathrm{c}}=10^{-6}$ shown in Figure 4) can be integrated numerically with $E \sim A_{0} \sigma_{\mathrm{c}} d \sum_{\left|\Delta \varepsilon_{Y}\right|>\varepsilon_{Y, \mathrm{c}}}\left|\Delta \varepsilon_{Y}\right|$, where $A_{0}$ is the grid area $(5 \mathrm{~km} \times 5 \mathrm{~km})$ and $\varepsilon_{Y, \mathrm{c}}$ is the threshold of incremental strain.

The estimated released energy is about $E \sim 8 \times 10^{18} \mathrm{~J}$, when $\varepsilon_{Y, \mathrm{c}}$ is taken to be $1 \times 10^{-6}$. Figure 5 shows the dependence of the released energy and the relevant area on the threshold of incremental strain $\varepsilon_{Y, \mathrm{c}}$. Obviously, with the strain increments $\left|\Delta \varepsilon_{Y}\right|>\varepsilon_{Y, \mathrm{c}}=10^{-6}$, the released energy $E \sim 10^{18.9} \mathrm{~J} \approx 8 \times 10^{18} \mathrm{~J}$ and the relevant area of about $10^{5.2} \mathrm{~km}^{2} \approx 2 \times 10^{5} \mathrm{~km}^{2}$ do characterize the Tohoku Earthquake.

\section{Conclusions and discussions}

The released energy during the Tohoku M9.0 earthquake is

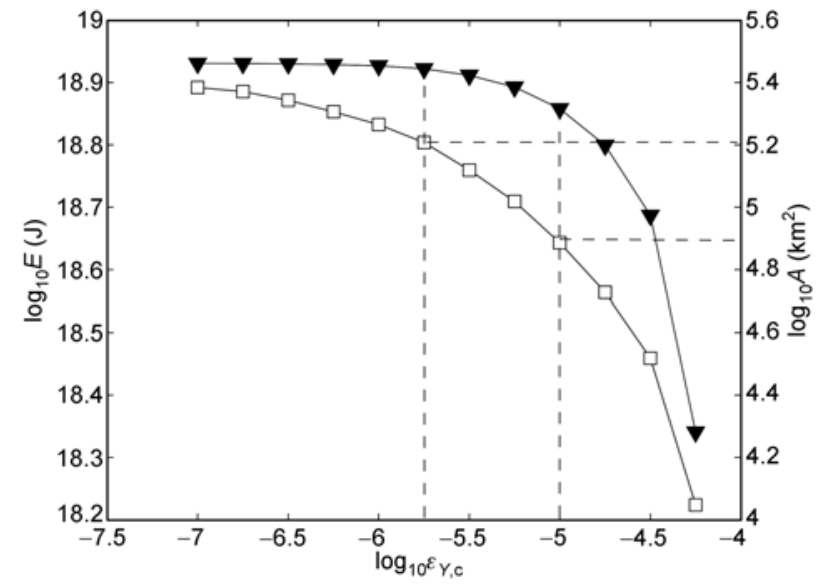

Figure 5 The dependence of the released energy $E(\boldsymbol{\nabla})$ and the area $A(\square)$ on the relevant region on the threshold of incremental strain $\varepsilon_{Y, \mathrm{c}}$. When the threshold $\varepsilon_{Y, \mathrm{c}}$ decreases to $10^{-5.75}$, the calculated released energy nearly stops increasing at $10^{18.9} \mathrm{~J}$ corresponding to the area $A \sim 10^{5.2} \mathrm{~km}^{2}$.

estimated as $8 \times 10^{18} \mathrm{~J}$. Notably, the released energy is in the same order of magnitude of the energy involved in seismic waves $E_{\mathrm{sw}} \sim 10^{4.8+M \times 1.5}=10^{4.8+9 \times 1.5} \approx 2 \times 10^{18} \mathrm{~J}$ (notice that the seismic wave energy of aftershocks is merely $\sim 10^{15} \mathrm{~J}$ in accord with the earthquake catalogue provided by NEIC (www.usgs.gov)), but greater than the latter. Since the energy involved in seismic waves is just a fraction of the total energy dissipation in an earthquake, the above comparison of the two energies is reasonable. Additionally, the estimated released energy must be a lower bound of the total released one, since only the energy related to the incremental component of strain $\Delta \varepsilon_{Y}$ is calculated. All these indicate that an earthquake should be a self-sustained catastrophic process and the energy dissipation associated with earthquake is specifically provided by the adjacent elastic unloading body.

The unloading strain increments $\left|\Delta \varepsilon_{Y}\right|>\varepsilon_{Y, \mathrm{c}}=10^{-6}$ and the relevant area of $\sim 2 \times 10^{5} \mathrm{~km}^{2}$ (roughly $400 \mathrm{~km} \times 500 \mathrm{~km}$ to the northwest of the faults) are the other two characteristic features of Tohoku Earthquake owing to their close relation to the energy release in Tohoku Earthquake. Obviously, the relevant area covers most part of the eastern Japan, slightly beyond the west coast of Japan, but not very much (see the bold white contour in Figure 4). Additionally, the region of about $10^{4.9} \mathrm{~km}^{2} \sim 160 \mathrm{~km} \times 500 \mathrm{~km}$ with normal strain increments $\left|\Delta \varepsilon_{Y}\right|>10^{-5}$ contributes about $90 \%$ of the estimated released energy.

This work is supported by National Natural Science Foundation of China (Grant Nos. 90715001, 10721202, 10972218, 40974022, 11021262) and National Basic Research Program of China (Grant No. 2007CB814803). We would like to acknowledge the helpful discussion with Prof. Chen Yong. The supports on relevant GPS data and reference from Dr. Gan Weijun and Prof. Sun Hanrong are greatly appreciated.

1 Okada Y. Preliminary report of the 2011 off the Pacific coast of To- 
hoku Earthquake. 2011.3.25, NIED http://www.bosai.go.jp/

2 Hao J L, Wang W M, Yao Z X. Source process of the $2011 M_{\mathrm{w}} 9.0$ Tohuko Japan earthquake. Sci China Earth Sci, 2011, doi: 10.1007/ s11430-011-4241-y

3 Bai Y L, Lu C S, Ke F J, et al. Evolution induced catastrophe. Phys Lett A, 1994, 185: 196-200

4 Bai Y L, Hao S W, Lu M F, et al. Damage evolution induced catastrophe and its signification in forecasting terrestrial disasters. J Terraspace Sci Eng, 2009, 1: 41-48

5 Hao S W. Localization, catastrophic rupture and critical singularity of heterogeneous brittle media. Doctor Dissertation. Beijing: Insti- tute of Mechanics, Chinese Academy of Sciences, 2007

6 Geospatial Information Authority of Japan. The 2011 off the Pacific coast of Tohoku Earthquake: Crustal deformation and fault model. Preliminary Report. 2011.3.14. http://www.gsi.go.jp/

7 Sandwell D T. Biharmonic Spline Interpolation of GEOS-3 and SEASAT altimeter data. Geophys Res Lett, 1987, 2: 139-142

8 Brings I C. Machine contouring using minimum curvature. Geophysics, 1974, 39: 39-38

9 Japan Coast Guard. 宮城県沖の海底が 24 メートル動く〜東北地 方太平洋沖地震に伴う海底の動き〜. 2011. http://www.kaiho. mlit.go.jp/ 